\title{
Análise das metodologias de avaliação da empregabilidade dos graduados em desporto de portugal
}

\author{
Analysis of methodologies for assessing the employability of sport \\ graduates in portugal \\ D. Miragaia, P.G. Carvalho
}

ARTIGO DE REVISÃO | REVIEW ARTICLE

\begin{abstract}
O objectivo deste artigo consiste na análise de metodologias utilizadas para monitorar e avaliar a empregabilidade dos graduados em Portugal na área de Desporto. A metodologia constou de uma consulta de literatura nacional e internacional para se clarificar o conceito de empregabilidade e suas implicações no desenho metodológico da avaliação da empregabilidade. Foram consultados inquéritos aplicados por entidades oficiais e analisada a coerência entre as dimensões/variáveis contempladas e o conceito de empregabilidade. Da análise realizada identificaram-se problemas de validade, fiabilidade, discriminação e comparabilidade entre estudos. Estes resultados indicam que é necessário encontrar uma nova forma de avaliar a empregabilidade. Sugere-se que essa avaliação seja realizada através da metodologia de triangulação (dados e investigadores) que consubstancie um projecto de investigação inter-institucional no futuro próximo.

Palavras-chave: empregabilidade, saídas profissionais, desporto, metodologia, triangulação
\end{abstract}

ABSTRACT

The purpose of this article is to analyze the methodologies used to monitor and evaluate employability of Portuguese graduated sport students. The consultation of national and international literature was carried to understand the significance of employability concept and its implications for the methodological design used in evaluation reports of employability. Questionnaires applied by official organizations were consulted and the coherence between the dimensions/variables uncovered and the concept of employability was examined. Problems of validity, reliability, discrimination and comparability between studies were identified, which suggests that it is required find new ways to evaluate employability. One possible way consists in the use of the methodology of triangulation (data, researchers) that integrates inter-institutional research.

Keywords: employability, career opportunities, sport, methodology, triangulation

Submetido: 08.09.2011 | Aceite: 02.04.2012

Dina Miragaia e Pedro G. Carvalho. UBI, CIDESD.

Endereço para correspondência: Dina Alexandra Marques Miragaia, Universidade da Beira Interior, Departamento de Ciências do Desporto, Convento de Sto. António, 6201-001 Covilhã, Portugal.

E-mail: miragaia@ubi.pt 


\section{Dinâmicas dos Mercados de Trabalho}

No início do século XX o conceito de empregabilidade servia para distinguir o potencial que as pessoas tinham de vir a estar empregadas numa sociedade industrial na altura pujante. Após a $2^{\mathrm{a}}$ Grande Guerra Mundial, a valorização pessoal através da obtenção de um curso superior era a garantia de entrada no mercado de trabalho, qualificado e seguro, considerando-se que a formação inicial era a necessária e suficiente para um emprego vitalício.

A crise económica, política e cultural nos anos 60 , nomeadamente a revolução estudantil, a crise do petróleo nos anos 70 e as inovações sociais e tecnológicas resultantes criaram um novo paradigma, levando os quadros mais qualificados a sentir necessidade de aperfeiçoar conhecimentos e as empresas a exercer uma forte pressão sobre as escolas superiores para que os seus cursos sejam adaptados e mais capazes de fornecerem treino essencial para a integração dos licenciados nas novas dinâmicas do mercado de trabalho. Tratou-se de um período de intensificação das mobilidades de pessoas, bens e capitais e os meios de comunicação retiram muitos países do isolamento.

Após a desregulamentação neoliberal dos mercados e da revolução tecnológica global (anos 80), o conceito de empregabilidade assume outra relevância; as pessoas tomaram consciência de que as suas qualificações não são eternas, que um curso ou profissão já não bastavam para a vida e que a sociedade e o mercado de trabalho lhes exigiam uma aprendizagem permanente se não quisessem ser excluídos.

Ficar desempregado com meia-idade colocava novos problemas à sociedade, agora dominada pelas novas tecnologias e por novas actividades económicas nas mais diversas organizações, incluídas as empresas e as universidades.

Para aqueles que se graduaram antes dos anos 80 , a sensação de que nada se sabia após o curso era a mesma de hoje em dia; contudo, essa mesma sensação era depressa ultrapassada com a experiência profissional, que rapidamente determinaria o rumo profissional. Após essa década, a sensação de nada saber torna-se mais generalizada uma vez que mesmo durante os cursos (na altura com a duração de 5 anos) se sentia bem a mudança rápida de conceitos trabalhados e das novas formas de vida social e profissional. É por essa altura que emergem os estudos destinados a seguir o percurso profissional dos estudantes que saem do Ensino Superior, reflectindo exactamente a necessidade de as organizações avaliarem a forma como formavam/educavam/treinavam. Contudo, a maior parte desses estudos converteram-se numa quase 'arma de arremesso de marketing' no mercado competitivo da formação superior; serão poucos os estudos que concluem pelo não sucesso da formação que realizam, ou seja, o indicador de empregabilidade é sempre positivo e faz parte da avaliação externa das escolas; quando conveniente, passa a fazer parte do marketing externo das escolas que procuram atrair estudantes com melhores médias de classificação de entrada.

São diversos os estudos que se têm baseado em conceptualizações completamente diferenciadas, pelo que a validade dos mesmos (ou seja, saber se estão a medir exactamente o que querem medir) pode ser posta em causa; por maioria de razão pode ser posta em causa a sua comparabilidade com outros estudos nacionais e muito menos poderão ser utilizados para comparabilidade internacional.

\section{o Conceito de Empregabilidade}

Actualmente é questionável se a principal razão que leva os alunos a escolher determinada Universidade está relacionado com as possibilidades de empregabilidade que poderão ter, como resultado do estatuto que esta detém. Através de uma interpretação económica pode concluir-se que a empregabilidade será sempre maior nas grandes áreas metropolitanas, uma vez que se relaciona mais com o ambiente e 
dinâmica socioeconómica regional do que com a qualidade do ensino ministrado.

É por isso importante que se definam os conceitos que se querem medir, sob pena de se estar a designar da mesma forma, coisas muito diferenciadas.

Gazier sistematiza o conceito de empregabilidade em sete dimensões que evoluíram ao longo do tempo, retrato/reflexo das novas configurações dos mercados de trabalho. As sete dimensões são designadas como a empregabilidade dicotómica, a empregabilidade sociomédica, a empregabilidade da política da força de trabalho, a empregabilidade de fluxo, a empregabilidade da performance no mercado de trabalho, a empregabilidade de iniciativa e a empregabilidade interactiva. Tendo como base o conceito de empregabilidade interactiva, que parte do princípio que a empregabilidade não depende unicamente dos indivíduos, McQuaid \& Lindsay propõem-nos uma abordagem holística que contempla três componentes inter-relacionadas: os factores individuais, as circunstâncias pessoais e os factores externos. Nesta abordagem, os factores individuais estão directamente associados às competências e aos saber-fazer; os factores pessoais dizem respeito aos valores e meio social envolvente (necessidade de ganhar um rendimento, ao tipo de cultura de trabalho e ao acesso aos recursos) e os factores externos dependerão essencialmente do ciclo económico e do contexto da região/ país (associados às dinâmicas do mercado de trabalho). Uma síntese destas abordagens pode ser consultada na figura 1 .

Em grande medida, esta conceptualização encaixa em teorias vindas de outras áreas disciplinares como a teoria do capital humano em Becker e as da psicologia sobre a forma de aquisição de competências e desenvolvimento de (oito) formas de inteligência em Gardner.

Nesta mesma linha de pensamento estamos de acordo com Almeida quando afirma que "a empregabilidade individual é condicionada pelas regras de funcionamento do mercado de trabalho, pelas dinâmicas dos ciclos económicos e depende, igualmente, da empregabilidade dos restantes membros do grupo profissional de pertença".

Cada vez mais a empregabilidade estará

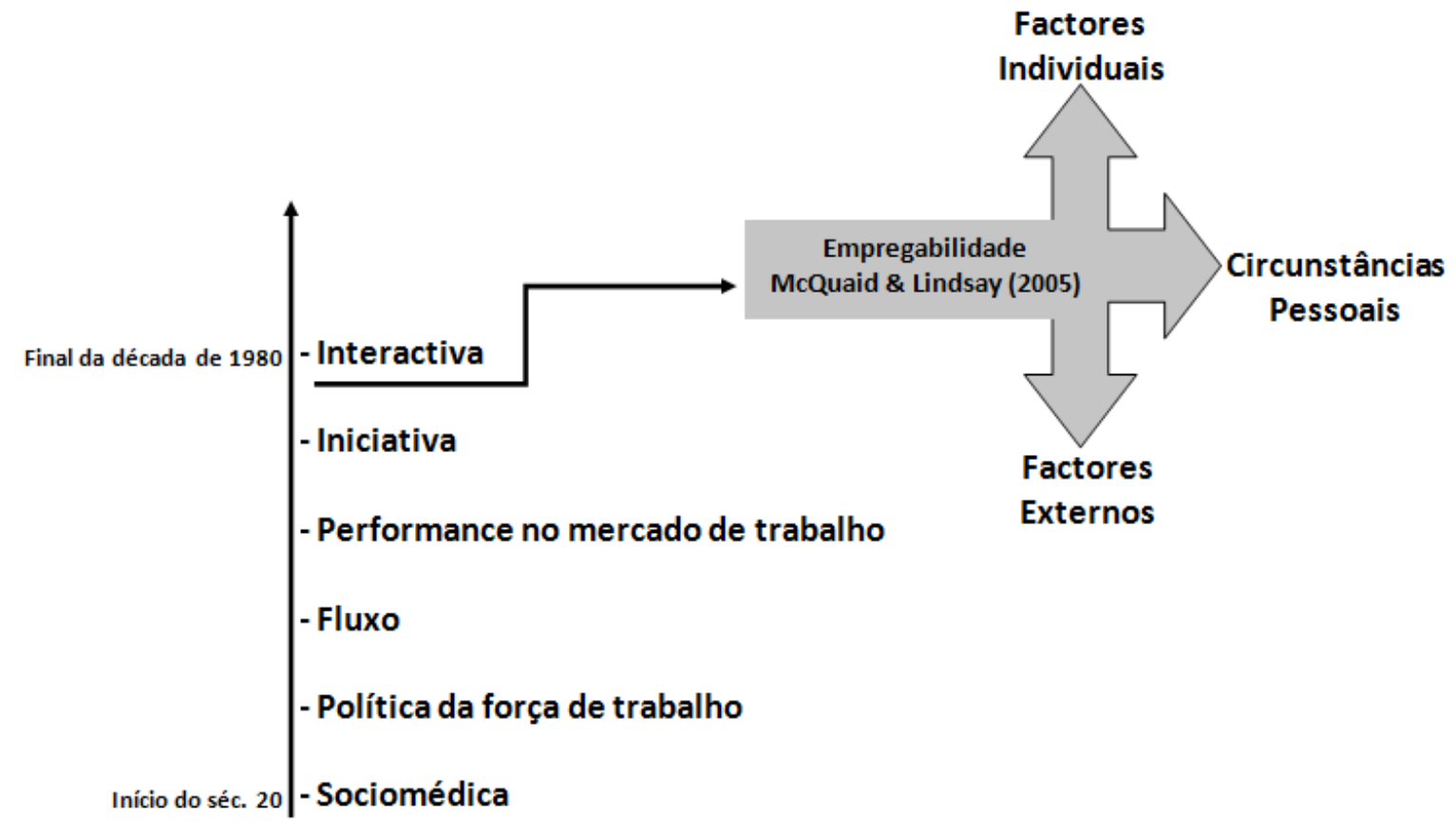

Evolução do Conceito de Empregabilidade (Gazier, 1998, 2001)

Figura 1: Conceitos de Empregabilidade 
baseada no trabalhador enquanto "profissional reflexivo" e não nos conteúdos iniciais da sua formação. A 'learning organization' será entendida como a organização onde os trabalhadores se desenvolvem constantemente aprendendo como se aprende.

$\mathrm{Na}$ mesma linha de raciocínio Almeida menciona Terssac que em 1994 refere que "as organizações que se baseiam no primado da qualificação dos seus actores assentam em três características básicas: (i) são organizações em que se torna possível gerir a incerteza própria de sociedades em mutação, opondo-se por isso as organizações prescritivas como são as tayloristas que pressupõem a existência de ambientes estáveis; (ii) são organizações dominadas por sistemas de comunicação horizontal entre os diferentes serviços e os diferentes centros de decisão, por oposição às organizações dominadas por sistemas de comunicação vertical centrados num único pólo de decisão e de produção de valores; (iii) são organizações nas quais os seus membros dispõem de autonomia e de capacidade de iniciativa para tomar decisões relativas ao trabalho a realizar". Deste modo, as organizações que apostam nesta conduta, ampliam a possibilidade de aumentar a empregabilidade dos seus trabalhadores.

\section{Implicações do Conceito de Empregabilidade na Dinâmica Organizacional}

Assim sendo, todas as organizações cuja principal missão é a de formar indivíduos e cidadãos, são parte interveniente de políticas públicas de emprego de cujo sucesso dependerá também a sua sustentabilidade no mercado das entidades de formação. É nesse contexto que analisamos a actual política de educação e ciência em Portugal e na UE, onde as avaliações externas funcionam como elementos de condicionamento financeiro das universidades e escolas públicas, obrigando-as a lutarem pela sua capacidade competitiva nacional e europeia.

Em suma, o conceito de trabalho alterou-se profundamente com o fim das linhas de produção em série; o que hoje existe são tarefas para serem feitas de forma rotineira e as principais tarefas de criação e inovação, para serem feitas por pessoas qualificadas e curiosas que pretendem encontrar novas formas de resolver problemas. Isso levou a que as actividades não tenham que ser exactamente realizadas num só local específico e que a empregabilidade seja uma capacidade de utilizar as suas competências e valores, seja qual for o ramo e o local para o qual seja necessário.

Num mundo cada vez mais especializado, começam também a ser necessárias as pessoas que sejam especialistas no todo, as que são capazes de se distanciarem das tarefas demasiadamente minuciosas para estudarem novos métodos e formas de abordar e resolver problemas em trabalho com outros, e de outras especialidades.

São diversos os estudos europeus, americanos, canadianos e australianos que abordam este assunto da empregabilidade, sempre na perspectiva da política do mercado de emprego. Estudos ora mais centrados no lado da procura por parte dos empregadores, ora na oferta por parte dos formadores. Mas o que acontece é que as características acima referidas por Terssac em 1994, mudam em função dos contextos, nomeadamente o maior ou menor desejo de os membros das organizações aceitarem certas condições de trabalho.

Seguindo esta linha de raciocínio parece imperioso reflectir sobre as nossas próprias experiências e descortinar as implicações que estas alterações de significação de conceitos devem ter nas organizações que formam cidadãos na área do desporto.

Pensar a escola que hoje forma profissionais na área do Desporto obriga-nos a ter estes aspectos organizacionais em consideração para nos tornarmos mais competitivos e, mais do que saber se os nossos alunos estão empregados ou se obtiveram um primeiro emprego/ profissão no tempo $\mathrm{X}$, importa saber qual a percepção que todos os actores envolvidos 
(universidade, estudantes, empregadores) têm sobre quanto da sua preparação para a autonomia lhes foi proporcionada na organização onde passaram uma parte importante da sua vida.

Nesse sentido julgamos mais adequado que as metodologias a utilizar para estudos sobre a empregabilidade incluam um estudo profundo e qualitativo de ambos os lados do mercado de trabalho.

\section{Análise Económica da Obtenção de uma Gra- duação em Desporto}

$\mathrm{Da}$ análise de inquéritos sobre empregabilidade, aplicados por entidades oficiais, foi possível verificar que uma das preocupações centrais é identificar se os seus alunos têm tido sucesso no mercado de trabalho através do estudo do período de tempo que demoram a encontrar o seu $1^{\circ}$ emprego após a formação inicial; identificar qual a sua remuneração; qual a mobilidade (por vezes), etc.

Por outro lado, em desporto, ainda não se deixou de considerar que o sucesso vem sobretudo da prática e que a formação só tem importância para quem quiser ensinar nas escolas básicas e secundárias, uma vez que todos os cursos que habilitam para treinar (uma das especialidades do ensino), são obtidas nas associações e federações de modalidade que não exigem pré-requisitos de ensino superior.

É verdade que o mundo do desporto começa a modificar-se e que, progressivamente, mais treinadores e desportistas de várias modalidades começam a ser pessoas com formação média e superior. Mas essa constatação ainda não se generalizou.

Saber se vale a pena obter formação em desporto não é mais do que uma preocupação estudada em torno do conceito económico de custo de oportunidade representado no gráfico 1.

Se considerarmos o eixo vertical como representativo do rendimento que se pode auferir com o exercício de uma profissão e o eixo horizontal como a idade de dois indivíduos A e B, podem comparar-se as diferentes trajectórias.

(i) O sujeito A optou por entrar no mercado de trabalho quando tinha 18 anos e manteve o seu percurso profissional com um rendimento que cresce marginalmente a taxa decrescente.

(ii) O sujeito B optou por estudar 5 anos no ensino superior, suportando os custos do estudo (área tracejada abaixo do eixo horizontal) e do não-emprego durante 5 anos (área tracejada acima do eixo horizontal); contudo obteve uma maior remuneração ao longo da

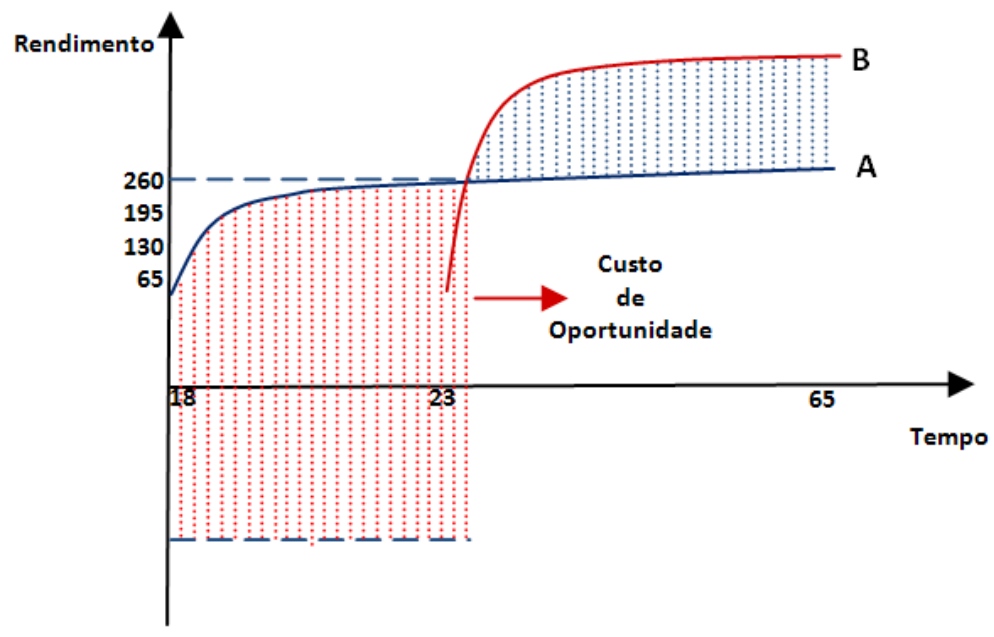

Fonte: Adaptado de Portugal (2004, p. 74)

Gráfico 1: A escolha entre rendimento atual ou futuro 
vida (representada pela área tracejada entre as duas linhas).

Da comparação destas duas áreas representadas a "trama" diferente, estaria a solução do problema, isto é, valeu a pena a licenciatura se a área de ganho acrescido mais que compensar a área de custo suportado. Os números que se apresentam no eixo vertical são os que foram apresentados no estudo de Portugal e expressos em contos/mês.

Num estudo mais recente, Torres corrobora esta análise, recordando as teorias do capital humano de Becker e da sinalização de Spence, que postulam que a educação é um investimento que mais tarde vai permitir aumentos de produtividade e quem tem um diploma, sinaliza as suas competências junto dos empregadores potenciais. Neste estudo, que cobre o período de 1998 - 2007 para Portugal, Torres conclui que a correlação entre nível de estudos e rendimento auferido é positiva e que este é de cerca de 2.38 vezes superior (cerca de $€$ $1.368,00$ ) ao dos empregados com níveis inferiores de formação.

Mas hoje em dia as coisas podem estar a alterar-se substancialmente, uma vez que nem sempre a formação superior garante as competências e atributos necessários para a obtenção de empregos numa determinada área. Mais ainda, estes estudos ainda não cobrem os graduados após licenciatura de Bolonha (3 anos).

Um caso exemplificativo no desporto poderia ser identificado como a comparação entre os treinadores que optaram por seguir a carreira logo a seguir a uma carreira como desportista e aqueles que entraram na carreira de treinador pela via académica. Está por se descobrir qual deles ganha hoje mais; contudo, é cada vez mais evidente que qualquer treinador, com e sem formação académica superior, não prescinde de novos profissionais detentores de áreas de conhecimento e experiências profissionais diversificadas.

Por outro lado, com a adequação das licen- ciaturas a Bolonha, o tempo de formação inicial tornou-se ainda mais curto e importa adequar estes estudos à nova realidade do mercado de trabalho nacional e internacional. Também na área do desporto essa reflexão se deve fazer, não se podendo ignorar o facto de as profissões na área do desporto terem ganho novas configurações ao longo dos tempos conduzindo diferentes países da Europa a níveis tão diferenciados.

Neste sentido não podemos deixar de mencionar o trabalho desenvolvido pelo European Observatory of Sports Occupations onde se sugere uma classificação em que distingue "actividades do desporto" e "actividades relacionadas com o desporto". Esta proposta resultou da participação de representantes de diversos países da Europa (incluindo Portugal) e a European Network of Sport Sciences in Higher Education. A definição de uma classificação única não é fácil uma vez que é necessário salvaguardar as especificidades do contexto de cada país do ponto de vista das actividades económicas relacionadas com o desporto. A forma encontrada por esta comissão é expressa do seguinte modo: "We will adopt a broad definition of sport, which means that we will take into account not only the activities run within the organized sport movement but also the physical activities developed as a mean of education, of recreation, of health development or care, of performance including the production of spectacles. Following this perspective, sport can be considered both as a product of consumption (good or service) and as an investment good (human capital)".

A proposta tem como base a Classificação de Actividades da Europa Comunitária (NACE), que integra as actividades desportivas na secção $O$ (outras Comunidades, serviços pessoais e sociais), divisão 92 (actividades recreativas, culturais e desportivas) e no grupo 92.6 que enquadra as actividades desportivas e as desagrega em duas classes: classe 92.61 (funcionamento de campos e estádios) e classe 
92.62 (outras actividades desportivas). Porém, sugere-se a necessidade de se fazer uma maior desagregação das classes até aos 6 dígitos. Deste modo a classificação sugerida resulta nos seguintes dados: (i) Actividades do Desporto: 1 secção, 1 Divisão, 1 grupo e em 66 classes; (ii) Actividades Relacionadas com Desporto: 9 secções, 8 sub-secções, 29 divisões, 51 grupos, 99 classes. Esta proposta reflecte a complexidade e a dimensão das actividades económicas que envolvem o desporto e que traduzem a amplitude e oportunidade profissional desta área para além das profissões convencionais mais consideradas.

\section{Lacunas Metodológicas Encontradas nos Estu-} dos Nacionais e Internacionais sobre Empregabilidade

Com base no exposto analisaram-se trabalhos empíricos sobre a temática do emprego e empregabilidade desenvolvidos por entidades nacionais e internacionais que passaremos a indicar. O Inquérito ao Emprego foi elaborado pelo Instituto Nacional de Estatística com o objectivo central de obter informação sobre o estado de emprego/desemprego da população activa, bem como o de conseguir o registo da população inactiva.

Em território nacional a monitorização e análise do emprego de forma sistemática surge em 1974, através do inquérito ao emprego que foi sendo actualizado ao longo de várias décadas, como resultado de alterações sobre o entendimento deste tema. Em virtude da necessidade de comparabilidade internacional do emprego em 1983 foi feita uma aproximação com os indicadores utilizados no inquérito comunitário (Labour Force Survey) e em 1998 através do regulamento $n^{\circ} 577 / 98$ proferido pelo Conselho da União Europeia é finalizado o processo de integração de variáveis obrigatórias para a análise do emprego em espaço Europeu e seguindo os conceitos recomendamos pela Organização Internacional do Trabalho (OIT). "Existem actualmente quatro séries temporais do Inquérito ao Emprego: Série74 (1974-1982), Série83 (1983-1991), Série92 (1992-1997) e Série98 (a partir de 1998)".

Perante novas configurações do mercado de trabalho passa a ser necessário definir indicadores mais específicos, para reunir elementos que servissem para uma intervenção e monitorização de políticas no mercado de trabalho. Deste modo foram projectados vários inquéritos, designados de modelos ad hoc, por um grupo de trabalho constituído por diversas entidades internacionais como o Eurostat, Organização Internacional do Trabalho (OTI), Banco Central Europeu, entre outras, das quais resultou um plano para aplicar entre 1999 e 2012. Desses modelos importa destacar: (i) Aprendizagem ao longo da vida, aplicado em 2003; (ii) Entrada dos jovens no mercado de trabalho, aplicado em 2009.

$\mathrm{O}$ inquérito ao trabalho aplicado à população portuguesa pelo Instituto Nacional de Estatística actualmente em vigor (2008-2010), está organizado em 14 dimensões de análise. No âmbito deste trabalho importa analisar particularmente a Educação/Formação Aprendizagem Formal e Educação/Formação - Aprendizagem não Formal, uma vez tratarem-se de dimensões relacionadas com as qualificações formativas obtidas ao longo da vida permitindo-nos analisar estes dados, com os dados recolhidos pela Instituições de Ensino Superior e por outro lado, analisar a relevância desta informação para uma melhor compreensão da empregabilidade.

A dimensão Educação/Formação - Aprendizagem Formal está organizada para obter de informação sobre a formação dos inquiridos em duas fases temporais distintas:

(i) Por um lado saber qual a formação anteriormente obtida pelo inquirido, no que se refere ao nível de escolaridade, ano de conclusão, intenção de o ter feito e indicação de qual a área de Educação/Formação em que se inseriu o curso (perguntas 85, 86, 87, 88). Acontece que as opções possíveis de assinalar 
nesta última são: Formação de professores/ formadores e ciências de educação; Artes e humanidades; Línguas e literaturas estrangeiras; Ciências sociais, comércio e direito; Ciências da vida; Ciências físicas; Matemática e estatística; Ciências informáticas; Informática na óptica do utilizador; Engenharia, indústrias transformadoras e construção; Agricultura, silvicultura, pescas e ciências veterinárias; Saúde e protecção social; Serviços; Não consegue classificar; Grande Grupo: Ciências, Matemática e Informática.

Ora, mais uma vez se constata a forma como são tratadas estatisticamente, as profissões da área do desporto; tal classificação não permite a comparabilidade com outros estudos, nomeadamente com o relatório publicado pelo Gabinete de Planeamento, Estratégia, Avaliação e Relações Internacionais do Ministério da Ciência, Tecnologia e Ensino Superior sobre a procura de emprego dos diplomados com habilitação superior, onde se utiliza outra sistematização das áreas de formação. Como será possível avaliar especificamente qual a informação correspondente aos inquiridos com formação na área do desporto?

Por sua vez, o Ministério da Ciência, Tecnologia e Ensino Superior distingue a classificação de serviços em pessoais, sociais, de transporte e segurança, classificando os cursos de Ciências do Desporto e Educação Física como Área 81 Serviços Pessoais, em que se inclui também a Gestão Hoteleira e Turismo.

Perante o exposto considera-se que a utilização de classificações diferenciadas e que incluem várias áreas em simultâneo não permite distinguir rigorosamente, de entre os resultados sobre o emprego nacional, quais os que se referem especificamente ao desporto.

(ii) A outra fase temporal referenciada no Inquérito ao Emprego tem como finalidade saber se o inquirido, no momento da aplicação do questionário ou nas 3 semanas anteriores, está a frequentar (ou não) algum nível de escolaridade ou curso com equivalência escolar e saber se a intenção de frequentar é para prosseguir os estudos ou para inserção na vida profissional (perguntas 90, 91, 92). Esta informação permite saber de uma forma global se o indivíduo está a apostar na formação ao longo da vida, contudo, o que poderá apenas ser concluído é a percentagem (\%) de pessoas que o estão a fazer (ou não), qual o nível de escolaridade que estão a frequentar e a intenção de o fazer.

O mesmo se passa em relação à dimensão Educação/Formação - Aprendizagem não Formal que procura saber se o inquirido naquele momento ou nas 3 semanas anteriores frequentou algum curso fora do sistema de educação e formação, como seminários, conferências, entre outras; a quantidade de horas passadas nas actividades leccionadas; e qual o motivo pelo qual o inquirido frequentou o curso (razões profissionais/razões pessoais ou sociais) (perguntas 93, 94, 95).

Não deixando de os considerar importantes, não podemos deixar de mencionar que, do ponto de vista da tomada de decisões estratégicas para a empregabilidade, estes resultados ajudam muito pouco. Qual a relevância de saber quantas horas os inquiridos utilizaram naquela semana para a sua aprendizagem e qual o significado desta informação em relação às competências ganhas e sua implicação na empregabilidade dos inquiridos?

Perante o exposto podemos concluir que os inquéritos que recolhem elementos sobre o emprego em Portugal não permitem retirar elementos específicos sobre a empregabilidade da área específica do Desporto.

A empregabilidade também tem vindo a ser seguida pelos designados Observatórios de Estágios e Emprego incorporados nas Instituições de Ensino Superior que, de forma independente, se organizam para monitorar a empregabilidade dos seus licenciados. Contudo, os resultados destes trabalhos confinam-se essencialmente a uma utilização interna das Instituições.

A Universidade da Beira Interior (UBI) é 
um desses exemplos, e através do seu observatório tem aplicado um inquérito (2008) organizado em 4 dimensões de análise: (1) Identificação pessoal; (2) Dados Referentes à UBI; (3) Percurso Profissional; (4) Grau de Satisfação Relativo à Permanência na UBI.

Da análise feita a este inquérito importa destacar alguns aspectos relevantes sobre a importância da metodologia a utilizar para monitorar e analisar a empregabilidade. A referência teórica utilizada é a de Field que recorda que a eficiência de um questionário deve contemplar três elementos: Validade, Fiabilidade e Discriminação. Deste modo serão utilizados alguns exemplos para demonstrar que a utilidade dos dados obtidos através de um inquérito deverá ser salvaguardada aquando da sua elaboração.

Em inquéritos aplicados pelos Observatórios de Emprego integrados nas instituições formadoras é comum perguntar-se sobre qual a adequação dos conteúdos leccionados no curso frequentado às necessidades do mercado de trabalho. Repare-se que as respostas a esta questão podem trazer informação importantíssima para a redefinição dos planos pedagógicos a utilizar nos cursos. Contudo, esta pergunta só terá utilidade efectiva se identificar o mercado de trabalho onde o inquirido está a trabalhar e registada a opinião do empregador sobre o seu desempenho. Deste modo, consideramos conveniente que esta variável seja analisada do ponto de vista das competências, distinguindo entre competências técnicas e competências transversais. Se em alguns casos o inquirido pode ter desempenhado funções profissionais em diversos mercados de trabalho e considera que as competências técnicas apreendidas no seu curso estão desajustadas, não se pode deixar de fazer uma avaliação das competências transversais (ex: comunicação, línguas, autonomia, entre outras) que poderão ser utilizadas em outras profissões, mesmo que sejam "fora da área específica de formação" e neste caso, o curso teve igualmente uma interferência impor- tante, como pode ser visto num estudo recente de Cabral-Cardoso, Estêvão \& Silva, sobre a avaliação de empregadores e diplomados sobre a importância das competências transversais desenvolvidas nas instituições de ensino superior para o desempenho profissional.

Por outro lado, no tratamento dos dados sobre este tipo de questões é necessário acautelar dois elementos importantes: identificar qual o programa em vigor para cada uma das Unidades Curriculares que compôs um curso em determinado ano lectivo e considerar a eficiência pedagógica do corpo docente nesse período de tempo. Tal deverá ser feito através de uma metodologia de triangulação de dados e investigadores.

Na dimensão de registo do percurso profissional quando se procura saber se o inquirido se mantém no primeiro emprego ou se já passou por vários, quanto tempo demorou a obter emprego e em que região do país está a trabalhar, importa referir que estas respostas não estão directamente dependentes do que se designa ser a credibilidade da instituição de ensino superior detentora de cursos com "boas saídas profissionais”, mas também da conjuntura económica e de factores individuais como referido por Almeida. Deste modo, mais do que saber quantos empregos o inquirido já teve, importa fazer uma análise qualitativa das razões que estiveram associadas a este acontecimento.

A avaliação do grau de satisfação do inquirido sobre a sua permanência na instituição também é comum ser considerada nestes inquéritos. Sobre esta dimensão importa referir que, apesar de ser importante avaliar qual a satisfação do inquirido em relação a aspectos como o ambiente académico, as infra-estruturas e a capacidade pedagógicas dos docentes, uma vez que estes elementos podem ajudar os decisores institucionais a melhorar a qualidade dos seus serviços, não se pode esquecer que a avaliação deste 'circuito de produção' deve ter também o registo de qual a percepção das entidades empregadoras sobre as competências dos 
licenciados que acolhem. Deste modo importa saber quais são os atributos que as entidades empregadoras valorizam no recrutamento dos seus profissionais: estarão mais associadas às competências transversais? Às competências técnicas? Qual o peso atribuído ao facto de o candidato ter feito a sua formação na instituição de ensino superior X ou Y.

\section{Estudos Nacionais sobre a Empregabilidade na Área do Desporto}

No que se refere a informação específica e que esteja divulgada sobre a empregabilidade na área do desporto em Portugal foram escassos os elementos obtidos, destacando-se a seguinte informação retirada de três fontes distintas:

(i) Instituto de Desporto de Portugal no qual não consta nenhuma base de dados para o efeito.

(ii) Faculdade de Ciências do Desporto e Educação Física - Coimbra em que é feita a divulgação das percentagens de emprego obtidas pelos seus licenciados entre o período de 1999/2003 e com indicação adicional de que se trata de uma elevada taxa de empregabilidade. A variável de referência utilizada é tempo entre a conclusão de curso e obtenção do $1^{\circ}$ Emprego (6, 12, 18 meses).

(iii) Trabalho desenvolvido por Dinis, que incide no estudo das perspectivas de emprego e empregabilidade de alunos que ainda se encontram inscritos em cursos de Ciências do Desporto das Universidade: Ciências do Desporto e Educação Física da Universidade de Coimbra, Faculdade de Desporto da Universidade do Porto, Faculdade de Motricidade Humana da Universidade Técnica de Lisboa, Universidade da Madeira e Universidade de Trás-os-Montes e Alto Douro, mas que não permite obter informação sobre a empregabilidade efectiva destes alunos.

\section{Uma Proposta Metodológica Baseada na Triangulação}

Por todo o exposto sentimos que não se conseguirá prosseguir estudos nesta área da empregabilidade sem um esforço/projecto interdisciplinar e inter-institucional que possibilite encarar o problema de uma forma internacionalizada. Em nosso entender os próximos anos irão trazer novos elementos para a compreensão da competitividade das diversas escolas de formação em desporto em Portugal.

Sugere-se a utilização de uma metodologia que contemple a visão da empregabilidade do lado da oferta, do lado da procura e ao longo de vários anos, fazendo assim um estudo longitudinal, em profundidade e considerando as orientações de McQuaid \& Lindsay, quando mencionam que a compreensão holística da empregabilidade passa pela inter-relação de três elementos: os factores individuais, as circunstâncias pessoais e os factores externos.

Para esse efeito será necessário desenhar uma metodologia operativa em que se faça a triangulação de dados e investigadores, utilizando métodos quantitativos e qualitativos, de forma a avaliar qual é o posicionamento de diversos agentes (instituições formadoras, estudantes/licenciados, empregadores) sobre a problemática da empregabilidade. A opção de se propor uma metodologia em que se faz a triangulação quer de dados, quer de investigadores, resulta da necessidade de validação dos resultados.

\section{CONCLUSÕES}

Da literatura revista concluiu-se que a significação do conceito de empregabilidade tem sofrido alterações ao longo dos tempos. A divergência de utilização do mesmo conceito resulta na impossibilidade de comparabilidade entre diversos estudos produzidos sobre esta matéria, por entidades nacionais e internacionais. Sobre a empregabilidade em Portugal particularmente na área do desporto, para além da carência de estudos produzidos e publicados sobre esta matéria, constatou-se que os estudos produzidos por instituições públicas indiciam problemas de ordem metodológica. 
Os resultados apontam para a necessidade de desenvolvimento de uma metodologia de triangulação (dados e investigadores) envolvendo os diferentes actores intervenientes (instituições formadoras, estudantes/licenciados, empregadores), uma vez que a evolução do mercado competitivo exige que não se aborde a temática da empregabilidade apenas na escala nacional incentivando a uma cooperação inter-institucional para que se consiga projectar a formação portuguesa em desporto no mercado internacional.

\section{Agradecimentos:}

Nada declarado.

\section{Conflito de Interesses:}

Nada declarado.

Financiamento:

Nada declarado.

\section{REFERÊNCIAS}

Almeida, A. (2007). Empregabilidade, contextos de trabalho e funcionamento do mercado de trabalho em Portugal. Sísifo - Revista de Ciências da Educação, 2, 51-58.

Becker, G. (1962). Investment in human capital: a theoretical analysis. The Journal of Political Economy, 70(5), 9-49.

Becker, G. (1975). Human capital (2nd ed.): Columbia University Press.

Cabral-Cardoso, C., Estêvão, C., \& Silva, P. (2006). As competências transversais dos diplomados do ensino superior. Guimarães: TecMinho.

Cohen, L., Manion, L., \& Morrison, K. (2007). Research methods in education (6th ed.): Routledge.

Correia, M. J., \& Lima, F. (2006). O inquérito ao emprego: o que é e para que serve?, Estatísticas do Emprego $1^{o}$ trimestre: Instituto Nacional de Estatística, 37-40.

Dinis, F. (2007). Desporto, emprego e empregabilidade em portugal: perspetivas dos alunos de desporto do ensino universitário. Faculdade de Desporto Universi- dade do Porto, Porto, Portugal.

Edwards, A. (1999). Reflective practice in sport management. Sport Management Review, 2(1), 67-81.

European Observatory Of Sport Occupations - European Network Of Sport Sciences In Higher Education. (1997). European classification of sport and sport related economic activities: european observatory of sport occupations - european network of sport sciences in higher education.

Field, A. (2005). Discovering statistics using SPSS designing questionnaires (2nd ed.): SAGE publications Ltd.

Gabinete de Planeamento Estratégia Avaliação e Relações Internacionais / Ministério da Ciência Tecnologia e Ensino Superior. (2009). A procura de emprego dos diplomados com habilitação superior: gabinete de planeamento, estratégia, avaliação e relações internacionais / ministério da ciência, tecnologia e ensino superior.

Gardner, H. (1999). Intelligence reframed: multiple intelligences for the 21st century. New York: Basic Books.

Gazier, B. (1998). Employability-definitions and trends. In B. Gazier (Ed.), Employability: concepts and policies. Berlin: European Employment Observatory, 37-71.

Gazier, B. (2001). Employability: the complexity of a policy notion. In P. Weinert, M. Baukens, P. Bollérot, M. Pineschi-Gapenne \& W. Ulrich (Eds.), Employability: from theory to practice: Transaction Pub, 3-23.

Instituto Nacional de Estatística. (2008). Inquérito ao emprego - documento metodológico: instituto nacional de estatística - departamento de estatísticas demográficas e sociais / serviços de estatística do mercado de trabalho.

McQuaid, R., \& Lindsay, C. (2005). The concept of employability. Urban Studies, 42(2), 197-219.

Mcskimming, C. (2007). An investigation to identify the key strategies Cardonald College can use to improve the employability of its students.

Observatório da Inserção Profissional dos Diplomados em Desporto e Educação Física. Acedido em 6-7-2009, de http://woc.uc.pt/fcdef/event/ 
dataNews.do? elementId $=176 \&$ tipo $=$ historico

Observatório do Emprego e Formação no Desporto. Acedido em 6-7-2009, de http://www.idesporto.pt/CONTENT/4/4_7/4_7.aspx

Portugal, P. (2004). Mitos e factos sobre o mercado de trabalho português: a trágica fortuna dos licenciados. Boletim Económico, Banco de Portugal, 73-80.

Senge, P. (1993). The fifth discipline: the art and practice of the learning organization: book review. Consulting Psychology Journal: Practice and Research, 45(4), 31-32.

Skinner, J., Zakus, D., \& Cowell, J. (2008). Development through sport: building social capital in disadvantaged communities. Sport Management Review, 11 (3), 253-275.
Spence, M. (1973). Job market signalling. Quarterly Journal of Economics, 87, 355-374.

Torres, S. (2007a). Os módulos ad hoc do Inquérito ao Emprego. Principais resultados do módulo ad hoc de 2005: conciliação da vida profissional com a vida familiar, Estatística do Emprego $1^{\circ}$ trimestre: Instituto Nacional de Estatística, 37-47.

Torres, S. (2007b). População empregada e desempregada por nível de escolaridade - breve análise descritiva, Estatística do Emprego $4^{\circ}$ trimestre: Instituto Nacional de Estatística, 53-59.

Wittekind, A., Raeder, S., \& Grote, G. (2009). A longitudinal study of determinants of perceived employability. Journal of Organizational Behavior, $31(4), 566-586$.

(cc) EY-NC Todo o conteúdo da revista Motricidade está licenciado sob a Creative Commons, exceto quando especificado em contrário e nos conteúdos retirados de outras fontes bibliográficas. 